Clinical study

\title{
Circulating brain injury biomarkers increase after endoscopic surgery for pituitary tumors
}

\author{
Tobias Hallén $^{\mathrm{a}, \mathrm{b}, *}$, Daniel S. Olsson ${ }^{\mathrm{c}, \mathrm{d}}$, Casper Hammarstrand ${ }^{\mathrm{d}}$, Dan Farahmand ${ }^{\mathrm{a}, \mathrm{b}}$, \\ Ann-Charlotte Olofsson ${ }^{c}$, Eva Jakobsson Ung ${ }^{\text {d,e }}$, Sofie Jakobsson ${ }^{\text {e }}$, Henrik Bergquist ${ }^{\mathrm{f}, \mathrm{g}}$, Kaj Blennow ${ }^{\mathrm{h}, \mathrm{i}}$, \\ Henrik Zetterberg ${ }^{\text {h,i,j,k }}$, Gudmundur Johannsson ${ }^{\mathrm{c}, \mathrm{d}, 1}$, Thomas Skoglund ${ }^{\mathrm{a}, \mathrm{b}, 1}$
}

${ }^{a}$ Department of Neurosurgery, Sahlgrenska University Hospital, Gothenburg, Sweden

${ }^{\mathrm{b}}$ Department of Clinical Neuroscience, Institute of Neuroscience and Physiology, The Sahlgrenska Academy, University of Gothenburg, Gothenburg, Sweden

${ }^{\mathrm{c}}$ Department of Medicine, Sahlgrenska University Hospital, Gothenburg, Sweden

${ }^{\mathrm{d}}$ Department of Internal Medicine and Clinical Nutrition, Institute of Medicine, The Sahlgrenska Academy, University of Gothenburg, Gothenburg, Sweden

e Institute of Health and Care Sciences, The Sahlgrenska Academy, University of Gothenburg, Gothenburg, Sweden

${ }^{\mathrm{f}}$ Department of ENT/HEN Surgery, Sahlgrenska University Hospital, Gothenburg, Sweden

${ }^{\mathrm{g}}$ Department of Otorhinolaryngology, Institute of Clinical Sciences, The Sahlgrenska Academy, University of Gothenburg, Gothenburg, Sweden

${ }^{\mathrm{h}}$ Department of Psychiatry and Neurochemistry, Institute of Neuroscience and Physiology, The Sahlgrenska Academy, University of Gothenburg, Mölndal, Sweden

${ }^{\mathrm{i}}$ Clinical Neurochemistry Laboratory, Sahlgrenska University Hospital, Mölndal, Sweden

${ }^{\mathrm{j}}$ Department of Neurodegenerative Disease, Institute of Neurology, University College of London, London, UK

${ }^{\mathrm{k}}$ UK Dementia Research Institute, University College of London, London, UK

\section{A R T I C L E I N F O}

\section{Article history:}

Received 27 October 2020

Accepted 25 April 2021

\section{Keywords:}

Endoscopic transsphenoidal surgery

Biomarkers

Glial fibrillary acidic protein

Neurofilaments

Pituitary tumors

Tau protein

\begin{abstract}
A B S T R A C T
Pituitary tumors and subsequent treatment with endoscopic transsphenoidal surgery (ETSS) may cause injury to suprasellar structures, causing long-term fatigue and neurocognitive impairment. A method to quantify brain injury after ETSS is not available. In this prospective, exploratory study of patients undergoing ETSS for pituitary tumors, a novel approach to detect possible neuronal damage is presented. Plasma concentrations of brain injury biomarkers (glial fibrillary acidic protein [GFAP], tau, and neurofilament light [NFL]) were measured the day before surgery, immediately after surgery, at day 1 and 5 , and at 6 and 12 months after surgery, using enzyme-linked immunosorbent assays. The association between the increase of biomarkers with preoperative tumor extension and postoperative patient-perceived fatigue was evaluated. Suprasellar tumor extension was assessed from MRI scans, and self-perceived fatigue was assessed using the Multidimensional Fatigue Inventory before and 6 months after surgery. Thirtyfive patients were included in the analysis. Compared to baseline, GFAP showed a maximal increase at day 1 after surgery $(p=0.0005)$, tau peaked postoperatively on the day of surgery $(p=0.019)$, and NFL reached its maximum at day 5 after surgery $(p<0.0001)$. The increase in GFAP correlated with preoperative chiasmal compression $(\mathrm{p}=0.020)$. The increase in tau was correlated with preoperative chiasmal $(p=0.011)$ and hypothalamus compression $(p=0.016)$, and fatigue score 6 months after surgery $(p=0.016)$. In conclusion, the concentrations of brain injury biomarkers in blood increased after ETSS for pituitary tumors. The results indicate that postoperative plasma GFAP and tau might reflect astroglial and neuronal damage after ETSS.
\end{abstract}

( $) 2021$ The Author(s). Published by Elsevier Ltd. This is an open access article under the CC BY license (http://creativecommons.org/licenses/by/4.0/).

\section{Introduction}

Pituitary tumors account for approximately $15-20 \%$ of intracranial tumors $[1,2]$. The majority of pituitary tumors are benign ade-

\footnotetext{
* Corresponding author at: Department of Neurosurgery, Sahlgrenska University Hospital, Blå Stråket 5, 41345 Gothenburg, Sweden.

E-mail address: tobias.hallen@vgregion.se (T. Hallén).

1 These authors contributed equally.
}

nomas [3]. Other, less common lesions include craniopharyngiomas and Rathke's cleft cysts [4,5]. Although pituitary tumors are usually histologically benign, they can cause severe symptoms due to multiple endocrine deficiencies or compression of adjacent sensitive structures such as the optic chiasm, the hypothalamus, and the frontal lobes, causing long-term neurological and cognitive consequences [3,6,7]. Patients with pituitary tumors have been reported to have excess morbidity and mortality $[8,9]$. 
Surgery for pituitary tumors is most commonly performed using a transsphenoidal route with the assistance of a microscope or an endoscope [10]. This type of surgery is usually considered a procedure with a low risk of complications due to the fact that there often is an arachnoid layer between the tumor and the nervous structures. However, in some cases, manipulation of the structures adjacent to the tumor is unavoidable [11]. Many patients experience improvement of symptoms, such as visual disturbance, headache and health-related quality of life (HRQoL) after surgical decompression, but the possibility to identify the subgroup of patients that are at risk for a worsening in long term outcome would be beneficial. Previous studies assessing the impact of pituitary surgery on HRQoL have provided ambiguous results, with some reporting beneficial effects [12] and others not [13-15]. Symptoms such as fatigue, neurocognitive impairment, obesity, and sleep disorders have been reported, and although most of these problems probably are caused by inadequate endocrine replacement therapy, it has been proposed that in some cases these symptoms may be due to hypothalamic injury caused by the tumor and/or the surgical procedure [14-17]. Methods to measure minor damage to neuronal structures in relation to neurosurgery are not available. An early detection of brain injury after pituitary surgery would enable health care providers to initiate preventive measures for weight gain and coping strategies for cognitive dysfunction.

The possibility of using circulating levels of neuronal biomarkers to measure brain damage has gained increasing attention in recent years due to the development of novel ultrasensitive measurement techniques $[18,19]$. Increased plasma concentrations of neuronal biomarkers have been associated with the severity of injury and clinical outcomes in diseases such as traumatic brain injury and acute brain ischemia [20-24]. A limited number of studies have indicated that neuronal biomarkers can be used to predict neurological outcome after surgery for brain tumors $[25,26]$.

The primary aim of the present exploratory study was to study if an increase in circulating brain injury biomarkers glial fibrillary acidic protein (GFAP), tau, and neurofilament light (NFL) could be detected after transsphenoidal pituitary surgery and to explore the time profile of the postsurgical release of these neuronal biomarkers in plasma in order to determine the optimal timing for blood sampling in future studies. We also wanted to investigate the relationships between the biomarkers and perioperative factors and clinical outcome 6 months after surgery.

\section{Materials and methods}

\subsection{Patients}

The data was derived from the Gothenburg Pituitary Tumor (GoPT) study, a prospective study that is enrolling patients scheduled for pituitary surgery at Sahlgrenska University Hospital, which is the sole provider of neurosurgical services for 1.8 million people in the western region of Sweden. The study was approved by the Regional Ethical Review Board in Gothenburg, Sweden (Dnr: 387-15). Written consent was obtained from all participants prior to any intervention.

Between June 2016 and October 2017, 68 patients were admitted for pituitary surgery and 66 of these patients were included in the GoPT study (two patients were not included due to emergency surgery). Sequential blood sampling suitable for the present study was feasible in 35 (53\%) patients. Information about patient characteristics, including preoperative morbidity, clinical symptoms, hormone replacement therapy, preoperative visual field defects, and radiological findings was collected. Self-perceived fatigue was assessed preoperatively and 6 months after surgery using the Multidimensional Fatigue Inventory (MFI-20) [27] The MFI-
20 is a questionnaire that assesses five self-reported dimensions of fatigue (general fatigue, physical fatigue, reduced activity, mental fatigue, and reduced motivation).

\subsection{Anesthesia and surgical techniques}

All patients underwent endoscopic transsphenoidal resection of their pituitary tumor. General anesthesia was induced with propofol in all patients and maintained with volatile anesthesia (sevoflurane) and remifentanil/fentanyl or remifentanil only.

\subsection{Analysis of biomarkers}

Blood samples were collected the day before surgery, immediately after surgery, at day 1 and 5, and at 6 and 12 months after surgery. Blood samples (approximately $12 \mathrm{~mL}$ ) were collected in Vacutainer tubes, which were centrifuged for $10 \mathrm{~min}$ at $3800 \mathrm{rpm}$, and then 1-ml plasma aliquots were pipetted into cryotubes. The samples were stored at $-70{ }^{\circ} \mathrm{C}$ before being transported to the Clinical Neurochemistry Laboratory at Sahlgrenska University Hospital, Sweden, for analysis.

The concentrations of glial fibrillary acidic protein (GFAP) and total tau (t-tau) in plasma were measured using commercially available digital enzyme-linked immunosorbent assay (ELISA) reagents with a Single molecule array (Simoa) HD-1 Analyzer (Quanterix, Billerica, MA). The concentration of NFL in plasma was measured using in-house digital ELISA reagents on the Simoa platform, as previously described in detail [28]. All measurements were performed by board-certified laboratory technicians blind to clinical information. The samples were analyzed in two rounds of experiments ( $n=26$ and $n=9$, respectively). Importantly, paired samples from the same individual were analyzed in each run; for interpretation of the changes between the pre- and postoperative values, paired analysis was used, in that every patient served as his/her own control. The intra-assay coefficients of variation were below $10 \%$ for all biomarkers.

\subsection{Radiology}

All patients underwent magnetic resonance imaging (Philips Medical Systems Achieva dStream $3 \mathrm{~T}$ with gadolinium contrastenhanced T1-weighted sequences) before surgery. The DICOM image series were imported into the open-source software 3D Slicer (version 4.8.1, https://www.slicer.org/) using a PC and tumor volumes were calculated.

To grade the risk of possible manipulation of nervous structures during surgery, the preoperative suprasellar extension of the tumors was classified using coronal magnetic resonance images. The relationship to the optic chiasm and the hypothalamus was assessed as separate variables and the tumors were classified according to three grades for each of the two structures: 1) did not reach the suprasellar nervous structures (compression = none); 2) reached the chiasm or hypothalamus (compression = some); and 3 ) compression of the chiasm or hypothalamus (compression $=$ pro nounced) (Fig. 1).

\subsection{Statistics}

Patient characteristics are presented in the form of means \pm standard deviation (SD) or numbers with percentages. The pre- and postoperative levels of the biomarkers assumed a skewed distribution. Hence, non-parametric tests were used for statistical analyses. For visualizing the temporal profiles, both the absolute concentration change and the percentage change from baseline was used, while for higher statistical accuracy, all calculations were performed using absolute concentration changes from 


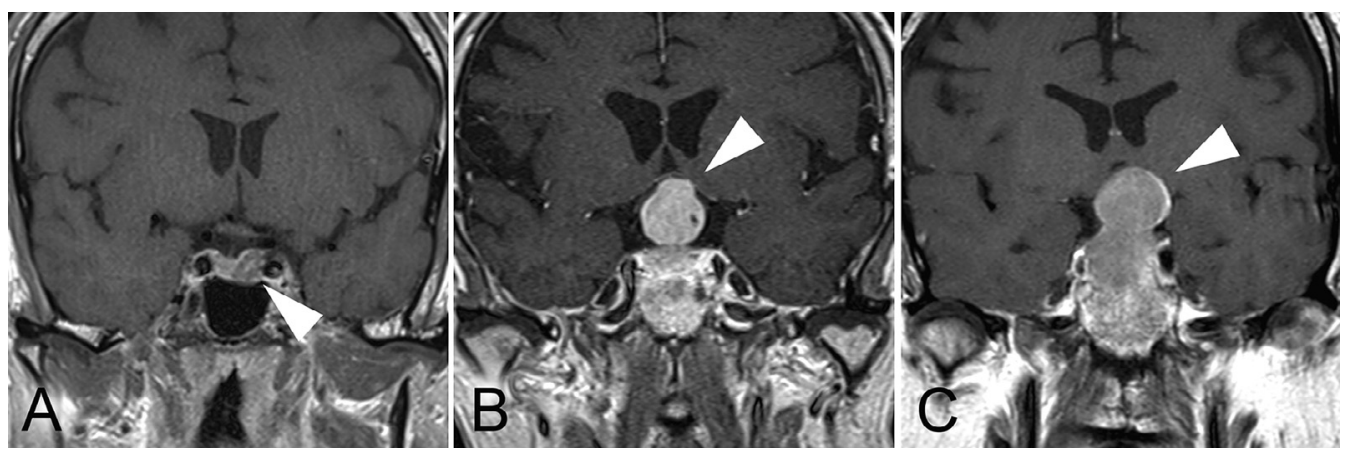

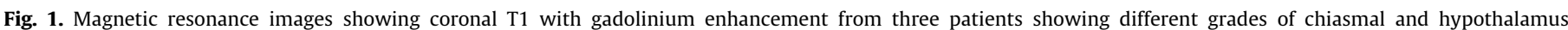

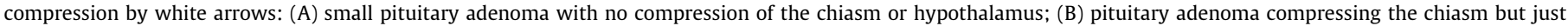
reaching the hypothalamus; and $(C)$ pituitary adenoma compressing the hypothalamus.

the baseline value [29]. For paired (longitudinal) data, the Wilcoxon signed-rank test was used and bootstrapping was performed to generate confidence intervals (CIs). For comparisons between groups, Spearman's correlation coefficient was used in the case of three or more groups with ordinal data; otherwise, a MannWhitney $U$ test was used. The correlations between continuous data values were assessed using Spearman's correlation coefficient. All tests were two-sided and $\mathrm{p}<0.05$ was considered significant.

Statistical tests were performed using SAS, version 9 (SAS Institute Inc., Cary, North Carolina, USA). The data were visualized using GraphPad Prism, version 8 (GraphPad Software, San Diego, California, USA).

\section{Results}

Thirty-five patients ( 20 men and 15 women) with a mean age of $60.2 \pm 15.9$ years were included in the study. The patient characteristics are presented in Table 1.

\subsection{GFAP}

GFAP concentration increased immediately after surgery and at postoperative days 1 and 5 , with the maximal increase observed on day 1 . From a baseline mean value of $127 \pm 73 \mathrm{pg} / \mathrm{ml}$, the absolute mean postoperative changes were $221 \mathrm{pg} / \mathrm{mL}$ (95\% CI 94-366 pg/ $\mathrm{mL}, \mathrm{p}=0.0017)$ immediately after surgery, $327 \mathrm{pg} / \mathrm{mL}(95 \% \mathrm{CI}$ $41-842 \mathrm{pg} / \mathrm{mL}, \mathrm{p}=0.0005)$ at day 1 , and $72 \mathrm{pg} / \mathrm{mL}(95 \% \mathrm{CI} 15-$ $153 \mathrm{pg} / \mathrm{mL}, \mathrm{p}=0.0003$ ) at day 5 . The baseline levels and the longitudinal postoperative changes in GFAP levels are presented in Fig. 2 and Table 2. Baseline levels and peak GFAP levels at day 1 were used for further statistical analysis.

The preoperative levels of GFAP correlated with age ( $p<0.001)$ but not with tumor volume, gender, tumor type, or degree of chiasmal or hypothalamus compression. The increase in GFAP on day 1 correlated with the degree of chiasmal compression $(\mathrm{p}=0.020)$ and showed a tendency towards correlation with the degree of hypothalamus compression ( $p=0.077$ ) (Fig. 3). No correlation was observed between the increase in GFAP on day 1 and age, gender, tumor volume, tumor type, preoperative visual field defects, duration of anesthesia, perioperative cerebrospinal fluid leakage, or postoperative new hormone replacement therapy.

\subsection{Tau}

From a baseline mean value of $2.1 \pm 1.3 \mathrm{pg} / \mathrm{ml}$, the maximum postoperative absolute increase in tau concentration (mean $2.3 \mathrm{pg} / \mathrm{mL}, 95 \% \mathrm{CI} 0.6-4.2 \mathrm{pg} / \mathrm{mL}, \mathrm{p}=0.019$ ) was observed immediately after surgery. A decrease from baseline was observed at day 5
Table 1

Baseline demographic and clinical characteristics of the patients who underwent endoscopic transsphenoidal surgery for pituitary tumors $(\mathrm{N}=35)$.

\begin{tabular}{|c|c|}
\hline Age (years) mean (SD) & $60.2(15.9)$ \\
\hline \multicolumn{2}{|l|}{ Gender, no. (\%) } \\
\hline Male & $20(57)$ \\
\hline Female & $15(43)$ \\
\hline \multicolumn{2}{|l|}{ Preoperative comorbidities, no. (\%) } \\
\hline Ischemic heart disease & $3(9)$ \\
\hline Ischemic stroke & $3(9)$ \\
\hline Diabetes mellitus type II & $7(20)$ \\
\hline Hypertension & $15(43)$ \\
\hline Psychiatric illness & $5(14)$ \\
\hline Heart failure & $1(3)$ \\
\hline Cancer & $5(14)$ \\
\hline Other & $20(57)$ \\
\hline \multicolumn{2}{|l|}{ Preoperative hormone deficiency, no. (\%) } \\
\hline TSH & $16(46)$ \\
\hline Sex steroids & $15(43)$ \\
\hline Growth hormone & $9(26)$ \\
\hline Adrenal insufficiency & $11(31)$ \\
\hline \multicolumn{2}{|l|}{ Preoperative VFD, no. (\%) } \\
\hline Yes & $19(54)$ \\
\hline No & $16(46)$ \\
\hline \multicolumn{2}{|l|}{ Type of tumor, no. (\%) } \\
\hline Non-functioning pituitary adenoma & $19(54)$ \\
\hline Acromegaly (GH adenoma) & $3(9)$ \\
\hline Cushings disease (ACTH adenoma) & $2(6)$ \\
\hline Cyst & $3(9)$ \\
\hline Craniopharyngeoma & $2(6)$ \\
\hline Prolactinoma & $3(9)$ \\
\hline Uncertain & $1(3)$ \\
\hline Other & $2(6)$ \\
\hline Tumor volume $\left(\mathrm{cm}^{3}\right)$, mean $(\mathrm{SD})$ & $6.2(5.6)$ \\
\hline \multicolumn{2}{|l|}{ Chiasmal compression, no. (\%) } \\
\hline None & $7(20)$ \\
\hline Some & $5(14)$ \\
\hline More & $23(66)$ \\
\hline \multicolumn{2}{|l|}{ Hypothalamus compression, no. (\%) } \\
\hline None & $18(51)$ \\
\hline Some & $7(20)$ \\
\hline More & $10(29)$ \\
\hline \multicolumn{2}{|l|}{ Type of anesthesia, no. (\%) } \\
\hline Propofol, sevoflurane and remifentanil & $30(86)$ \\
\hline Propofol, sevoflurane and fentanyl & $2(6)$ \\
\hline Propofol and remifentanil & $3(9)$ \\
\hline \multicolumn{2}{|l|}{ Perioperative CSF leakage, no. (\%) } \\
\hline None & $16(46)$ \\
\hline Some & $15(43)$ \\
\hline Profuse & $4(11)$ \\
\hline Baseline MFI total score (fatigue), mean (SD) & $60.2(20.9)$ \\
\hline Postoperative new hormone deficiency, no. (\%) & $16(46)$ \\
\hline
\end{tabular}

ACTH, adrenocorticotropic hormone; CSF, cerebrospinal fluid; GH, growth hormone; MFI, Mental Fatigue Inventory; SD, standard deviation; TSH, thyroid-stimulating hormone; VFD, visual field defects. 
A GFAP - mean change from baseline $(\mathrm{pg} / \mathrm{ml})$

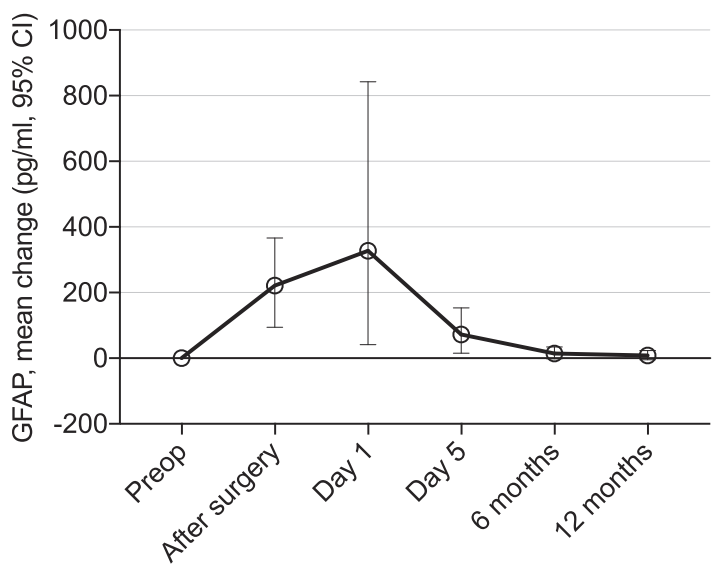

C Tau - mean change from baseline ( $\mathrm{pg} / \mathrm{ml})$

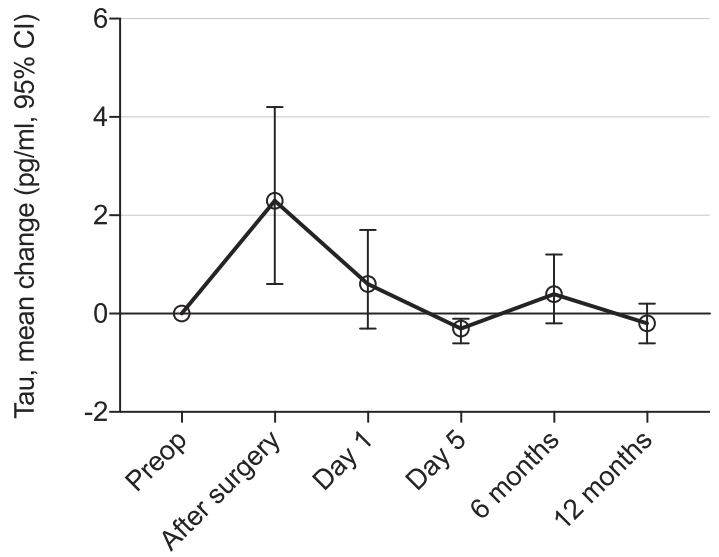

E $\quad \mathrm{NFL}$ - mean change from baseline $(\mathrm{pg} / \mathrm{ml})$

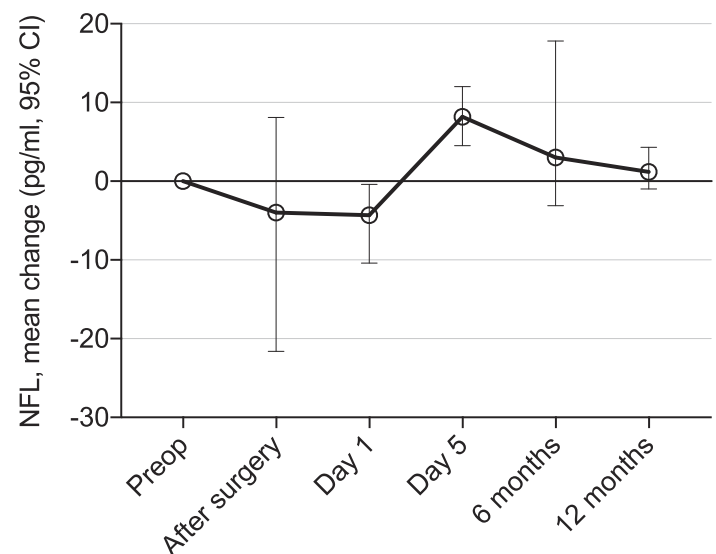

B GFAP - individual change from baseline (\%)

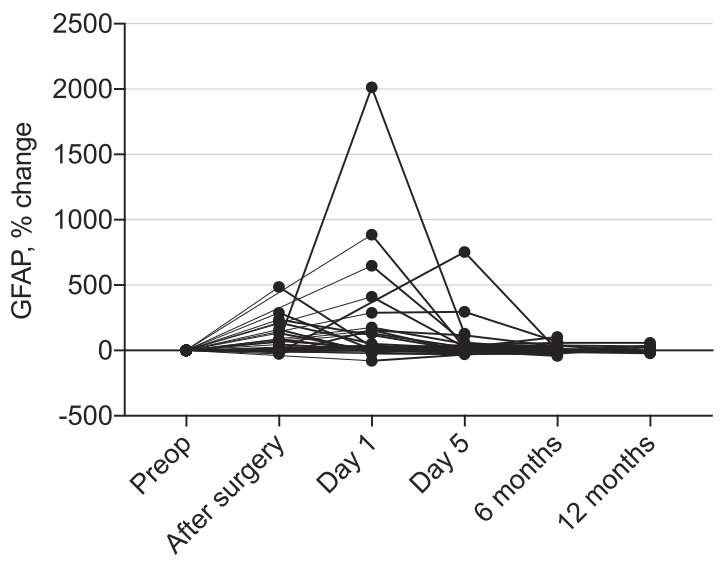

D Tau - individual change from baseline (\%)

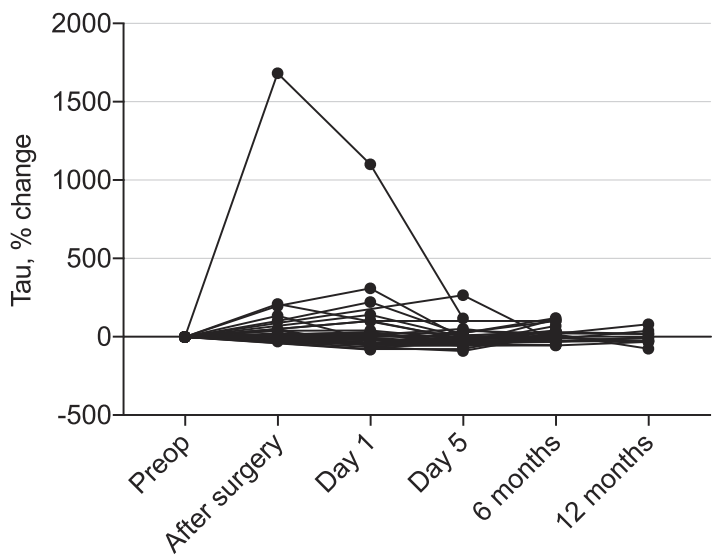

F NFL - individual change from baseline (\%)

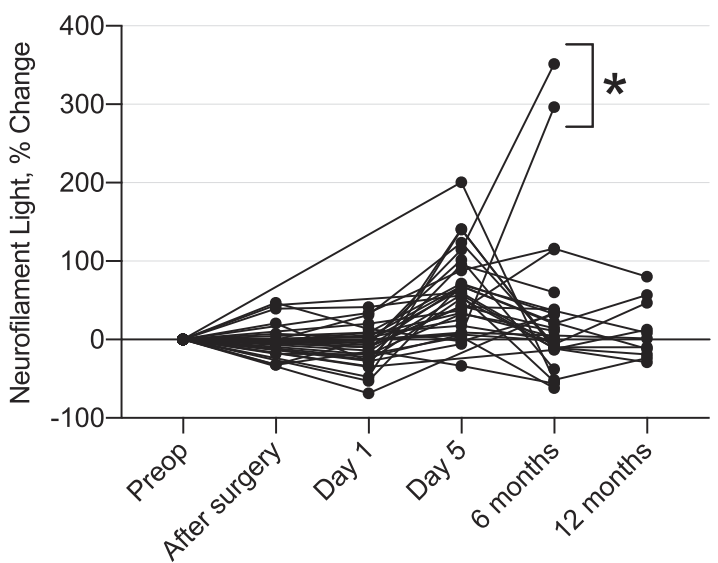

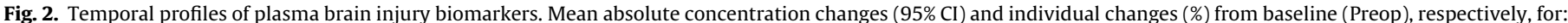

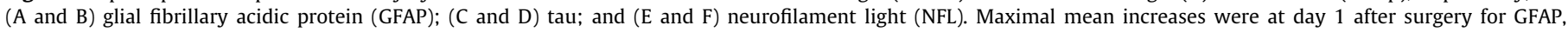

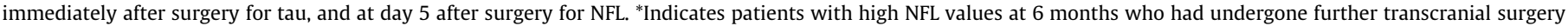
and radiotherapy. 
Table 2

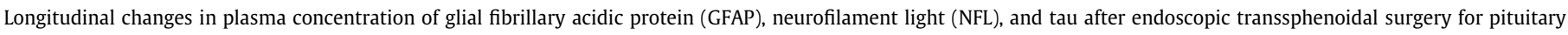
tumors.

\begin{tabular}{|c|c|c|c|c|c|c|c|}
\hline \multirow[t]{2}{*}{ Timepoint } & \multirow[t]{2}{*}{ Variable } & \multicolumn{2}{|l|}{$\operatorname{GFAP}(\mathrm{n}=35)$} & \multicolumn{2}{|l|}{ NFL $(n=35)$} & \multicolumn{2}{|l|}{ Tau $(\mathrm{n}=34)$} \\
\hline & & $\begin{array}{l}\text { Mean } \pm \text { SD } \\
(95 \% \mathrm{CI}) \\
{[\text { no., \%] }}\end{array}$ & $\begin{array}{l}\text { P-value } \\
\text { within } \\
\text { group }\end{array}$ & $\begin{array}{l}\text { Mean } \pm \text { SD } \\
(95 \% \mathrm{CI}) \\
{[\text { no., \%] }}\end{array}$ & $\begin{array}{l}\text { P-value } \\
\text { within } \\
\text { group }\end{array}$ & $\begin{array}{l}\text { Mean } \pm \text { SD } \\
(95 \% \mathrm{CI}) \\
{[\text { no., \%] }}\end{array}$ & $\begin{array}{l}\text { P-value } \\
\text { within } \\
\text { group }\end{array}$ \\
\hline Baseline & Absolute concentration $(\mathrm{pg} / \mathrm{mL})$ & $\begin{array}{l}127 \pm 73 \\
{[\mathrm{n}=35,100 \%]}\end{array}$ & NA & $\begin{array}{l}37.1 \pm 53.4 \\
{[\mathrm{n}=35,100 \%]}\end{array}$ & NA & $\begin{array}{l}2.1 \pm 1.3 \\
{[\mathrm{n}=34,97 \%]}\end{array}$ & NA \\
\hline $\begin{array}{l}\text { Immediately } \\
\text { after surgery }\end{array}$ & $\begin{array}{l}\text { Absolute concentration } \\
\text { difference from baseline }(\mathrm{pg} / \mathrm{mL})\end{array}$ & $\begin{array}{l}221 \pm 262 \\
(94 \text { to } 366) \\
{[n=14,40 \%]}\end{array}$ & 0.0017 & $\begin{array}{l}-4.0 \pm 29.2 \\
(-21.6 \text { to } 8.1) \\
{[n=14,40 \%]}\end{array}$ & 0.61 & $\begin{array}{l}2.3 \pm 3.4 \\
(0.6 \text { to } 4.2) \\
{[n=14,40 \%]}\end{array}$ & 0.019 \\
\hline Day 1 & $\begin{array}{l}\text { Absolute concentration } \\
\text { difference from baseline }(\mathrm{pg} / \mathrm{mL})\end{array}$ & $\begin{array}{l}327 \pm 1291 \\
(41 \text { to } 842) \\
{[n=32,91 \%]}\end{array}$ & 0.0005 & $\begin{array}{l}-4.3 \pm 15.7 \\
(-10.4 \text { to }-0.4) \\
{[n=32,91 \%]}\end{array}$ & 0.030 & $\begin{array}{l}0.6 \pm 3.0 \\
(-0.3 \text { to } 1.7) \\
{[n=32,91 \%]}\end{array}$ & 0.56 \\
\hline Day 5 & $\begin{array}{l}\text { Absolute concentration } \\
\text { difference from baseline }(\mathrm{pg} / \mathrm{mL})\end{array}$ & $\begin{array}{l}72 \pm 210 \\
(15 \text { to } 153) \\
{[n=33,94 \%]}\end{array}$ & 0.0003 & $\begin{array}{l}8.2 \pm 11.2 \\
(4.5 \text { to } 12.0) \\
{[n=33,94 \%]}\end{array}$ & $<0.0001$ & $\begin{array}{l}-0.3 \pm 0.7 \\
(-0.6 \text { to }-0.1) \\
{[n=32,91 \%]}\end{array}$ & 0.0091 \\
\hline Month 6 & $\begin{array}{l}\text { Absolute concentration } \\
\text { difference from baseline }(\mathrm{pg} / \mathrm{mL})\end{array}$ & $\begin{array}{l}14 \pm 51 \\
(-2 \text { to } 34) \\
{[n=29,83 \%]}\end{array}$ & 0.19 & $\begin{array}{l}3.0 \pm 17.8 \\
(-3.1 \text { to } 9.7) \\
{[n=29,83 \%]}\end{array}$ & 0.26 & $\begin{array}{l}0.4 \pm 1.9 \\
(-0.2 \text { to } 1.2) \\
{[\mathrm{n}=27,77 \%]}\end{array}$ & 0.45 \\
\hline Month 12 & $\begin{array}{l}\text { Absolute concentration } \\
\text { difference from baseline }(\mathrm{pg} / \mathrm{mL})\end{array}$ & $\begin{array}{l}8 \pm 24(-5 \text { to } 23) \\
{[n=11,31 \%]}\end{array}$ & 0.70 & $\begin{array}{l}1.2 \pm 4.6 \\
(-1.0 \text { to } 4.3) \\
{[n=11,31 \%]}\end{array}$ & 0.58 & $\begin{array}{l}-0.2 \pm 0.7 \\
(-0.6 \text { to } 0.2) \\
{[n=10,29 \%]}\end{array}$ & 0.68 \\
\hline
\end{tabular}

Wilcoxon signed-rank test was used for comparisons within groups.

(mean $-0.3 \mathrm{pg} / \mathrm{mL}, 95 \% \mathrm{CI}-0.6$ to $-0.1 \mathrm{pg} / \mathrm{mL}, \mathrm{p}=0.009$ ). The baseline levels and the longitudinal postoperative changes in tau levels are presented in Fig. 2 and Table 2. Baseline and peak tau levels immediately after surgery were used for further statistical analysis.

The preoperative levels of tau were not correlated with any patient or tumor characteristics. The increase in tau immediately after surgery correlated with the degree of chiasmal and hypothalamus compression ( $p=0.011$ and $p=0.016$, respectively) (Fig. 3). A greater increase was observed in patients with new postoperative hormone replacement therapy $(\mathrm{p}=0.035)$. Additionally, correlations were observed between an increased tau level immediately after surgery and tumor volume $(\mathrm{p}=0.033)$ and age $(\mathrm{p}=0.009)$. There were no correlations between the increase in tau immediately after surgery and gender, preoperative visual field defects, perioperative cerebrospinal fluid leakage, or duration of anesthesia.

\subsection{NFL}

From a baseline mean value of $37.1 \pm 53.4 \mathrm{pg} / \mathrm{ml}$, NFL concentration decreased postoperatively at day 1 (mean $-4.3 \mathrm{pg} / \mathrm{mL}$, $95 \% \mathrm{CI}-10.4$ to $-0.4 \mathrm{pg} / \mathrm{mL}, \mathrm{p}=0.03)$, whereas the maximal increase was observed at day 5 (mean $8.2 \mathrm{pg} / \mathrm{mL}, 95 \%$ CI $4.5-$ $12.0 \mathrm{pg} / \mathrm{mL}, \mathrm{p}<0.0001$ ). Baseline levels and the longitudinal postoperative changes in NFL levels are presented in Fig. 2 and Table 2. Baseline and peak NFL levels at day 5 were used for further statistical analysis.

The preoperative levels of NFL correlated with age $(p<0.001)$ and hypothalamic compression $(\mathrm{p}=0.038)$. The increase in NFL at day 5 did not show significant correlation with any patient or tumor characteristics.

One patient had highly increased preoperative NFL levels. This patient had undergone a percutaneous balloon compression to treat trigeminal neuralgia one month before the pituitary surgery (data not shown). Two patients showed highly increased NFL levels six months postoperatively (Fig. 2F). These patients had undergone further neurosurgery before the blood sampling at six months.

\subsection{Fatigue and biomarkers}

Fatigue measured as total MFI-20 score did not differ from baseline to 6 months after surgery $(p=0.360)$ for the whole cohort, but the individual change in total MFI-20 score showed a significant positive correlation with the increase in tau immediately after surgery $(p=0.016)$. There were no significant differences in fatigue between patients with or without new hormone deficiencies $(p=0.091)$. No correlations were found between the change in total MFI-20 score and the increase in GFAP at day 1 or with the increase in NFL at day 5 (Fig. 4).

\section{Discussion}

In this prospective exploratory study, we found that the plasma concentration of circulating brain injury biomarkers increased in patients who underwent endoscopic transsphenoidal surgery for pituitary tumors. For GFAP and tau, this increase correlated with a higher degree of preoperative suprasellar tumor extension and, for tau, also to self-perceived fatigue 6 months after surgery. This is to the best of our knowledge the first report showing that brain injury biomarkers in blood may be used to quantify the possible impact on nervous tissue during transsphenoidal pituitary tumor surgery.

\subsection{Brain injury biomarkers and release patterns}

GFAP is an intermediate filament protein that is almost exclusively present in the central nervous system and represents a major component of the cytoskeleton in astrocytes [30-32]. The release of GFAP in the bloodstream after trauma to the central nervous system indicates astroglial injury and/or activation and several reports have studied its utility as a biomarker in predicting clinical outcomes in traumatic brain injury (TBI) [33-35]. In our study, there was a significant postoperative increase in GFAP levels, reaching a peak at day 1 after surgery. The temporal profile was similar to that described after TBI [22].

Tau protein is highly expressed in the thin, non-myelinated axons of cortical interneurons [32,36]. Increased blood levels of tau have been observed in neurodegenerative diseases [37,38], after hypoxic brain injury [20], and after head trauma [39]. In our study, we observed a significant postoperative increase in tau levels immediately after surgery with a time profile that was similar to that described after head trauma [40].

NFL is a subunit of neuron-specific intermediate filaments and is most abundant in large-caliber myelinated axons that project 
A
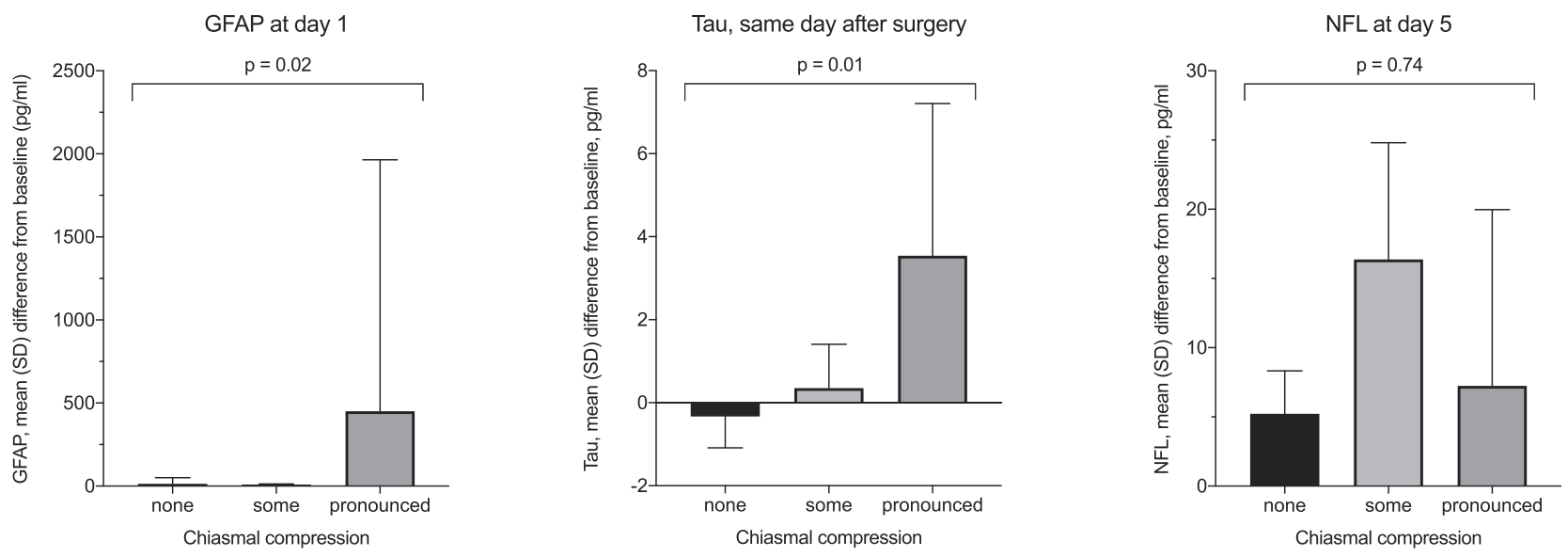

B

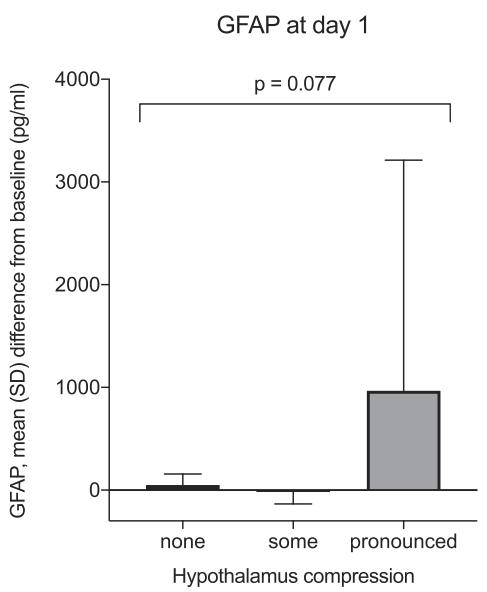

Tau, same day after surgery

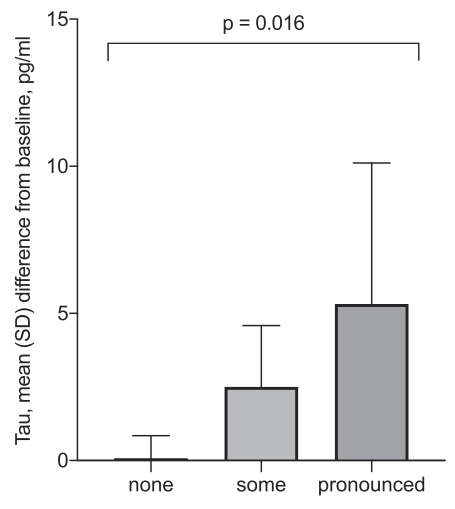

Hypothalamus compression
NFL at day 5

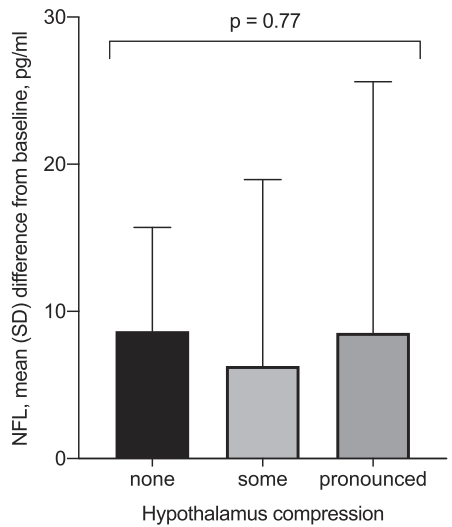

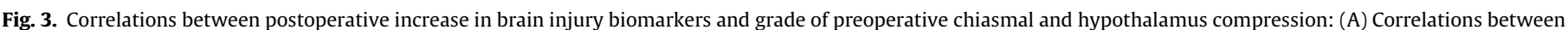

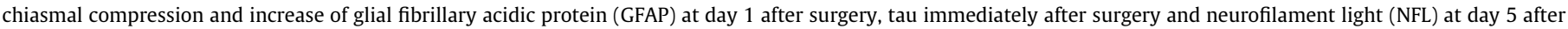

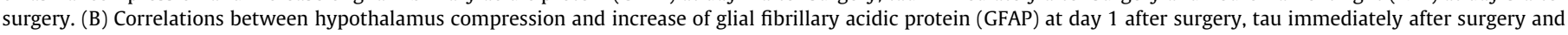
neurofilament light (NFL) at day 5 after surgery. Correlations were calculated using Spearman's correlation coefficient.
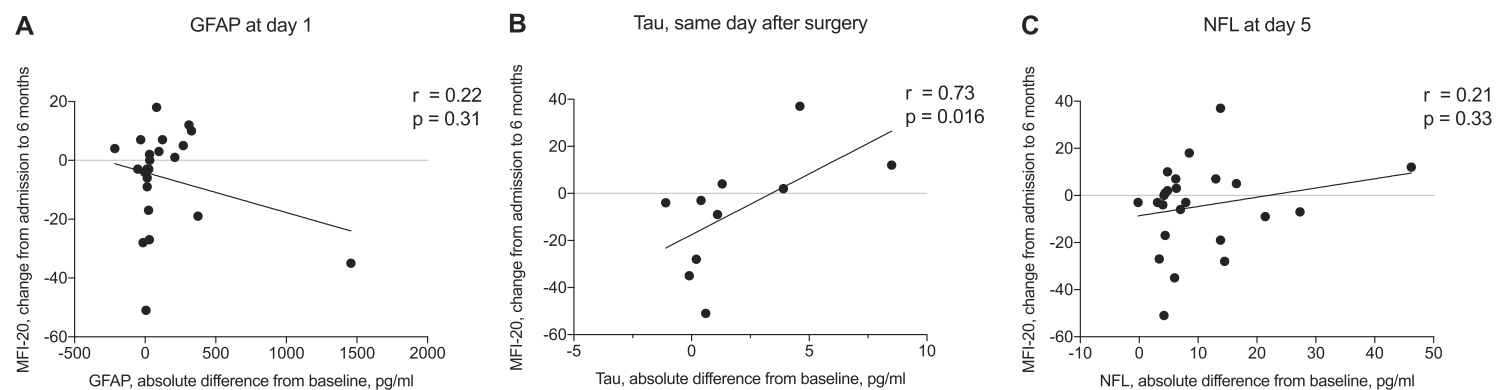

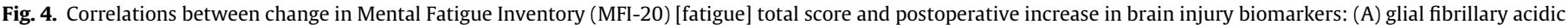

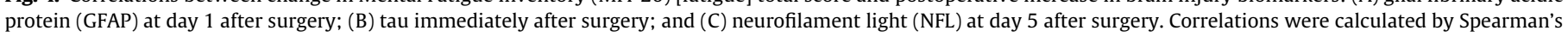
correlation coefficient. 
into deep brain layers and the spinal cord $[32,41]$. An increase in the serum concentration of NFL in neurodegenerative diseases and after head trauma has been described in several studies, and NFL seems to be the most sensitive circulating biomarker of axonal injury $[23,28,32,39]$. In the current study, peak NFL concentration was observed at day 5 after surgery, which is in agreement with other studies also showing a delayed release profile [22,42]. The results also show that there is no one single time point after surgery in which the different biomarkers can be collected as their peak plasma concentration is reached at different time points.

\subsection{Possible reasons for an increase in circulating brain injury biomarkers}

Although generally much lower levels than after TBI, the temporal profiles of the three biomarkers in our study strikingly resemble those found in other studies, which strengthens the evidence that detectable neuronal damage occurs in a subgroup of patients after endoscopic pituitary surgery. It has been speculated whether an increase in brain injury biomarkers can be due to the effect of the anesthesia $[42,43]$. However, in a recent study, with healthy volunteers undergoing general anesthesia without surgery, no increase in GFAP, tau or NFL were detected [43]. Another study, including patients undergoing functional endoscopic sinus surgery, a type of surgery comparable with ETSS without the transsellar dissection, did not show any significant postoperative increase of tau or NFL [44]. These findings indicate that anesthesia or sinonasal surgery not affecting the central nervous system have negligible effect on the release of brain injury biomarkers.

Hence, the findings in our study indicate that the increase of brain injury biomarkers could be a result of surgical manipulation of neuronal suprasellar structures. A significantly higher increase in GFAP at day 1 and in tau immediately after surgery were seen in patients with tumors compressing suprasellar structures compared to patients with tumors with no preoperative compression. In the latter group, which mainly constitutes patients with pure intrasellar tumors, the risk of manipulation of neuronal structures can be considered to be very low and, as expected, they have a significant lower increase in brain injury biomarkers. Possible mechanisms behind the perioperative release of GFAP and tau could be a direct damage, or release secondary to decompression, of neuronal and glial structures, which would be more likely with greater suprasellar tumor extension. We also noted a significantly higher increase in tau immediately after surgery in patients who required postoperative hormone replacement therapy. This may indicate that tau is more sensitive than the other biomarkers to surgical manipulation affecting the pituitary gland and its function.

The postoperative increase in NFL was not associated with any patient or tumor characteristics. However, data based on three of our cases indicates that NFL is sensitive to the manipulation of neuronal structures. One patient with a preoperative NFL value 3-times higher than the mean NFL value had undergone percutaneous balloon compression of the trigeminal nerve due to trigeminal neuralgia 1 month prior to pituitary surgery. The other two patients with remarkably high NFL values 6 months after the transsphenoidal surgery had both undergone additional transcranial surgery.

\subsection{Outcome after pituitary surgery}

The long-term outcome after pituitary surgery is dependent on multiple factors, and the impact of a possible brain injury caused by the tumor itself or its treatment is one. Neurocognitive sequelae due to damage of suprasellar structures have been suggested in previous studies [14-16]. If this damage could be detected through measurement of brain injury biomarkers, identification of patients with higher risk for a postoperative neurocognitive deterioration might be possible. Early initiation of preventive and/or supportive measures for e.g., sleep dysfunction, weight gain and coping strategies for cognitive impairment might be beneficial for these patients.

In our study, we could not demonstrate higher fatigue scores after 6 months on a group level, but it is interesting to note the positive correlation between the increase in tau values immediately after surgery and the change in the total MFI-20 score between baseline and 6 months after surgery. Higher tau concentration after surgery therefore seem to be related to a worsening, or at least a decreased improvement, in fatigue during the first 6 months after surgery. Since increased postoperative tau was also associated with new postoperative hormone deficiencies, it is impossible to conclude whether this relationship was caused by new hormone deficiencies or by an actual neuronal injury during surgery.

There are some limitations in the study. This is an explorative study with a small number of observations, not allowing for appropriate multivariable analyses. Sequential blood sampling was feasible in $53 \%$ of patients, which could pose a risk for selection bias. However, the practical reasons for not acquiring sequential blood sampling were considered to have resulted in a random dropout, and should not reflect a systematic error that would influence the results. Although all patients underwent the same type of surgery, the tumor diagnoses were heterogeneous. The study does not include a formal control group, but patients with tumors without suprasellar extension were included, where the risk of manipulation of neuronal and astroglial structures could be considered minimal. The increase of GFAP and tau were lower among these patients than in those with suprasellar extension. However, our results need to be confirmed in other studies where appropriate control groups are included in order to further understand the mechanisms and clinical importance of our findings.

\section{Conclusion}

In conclusion, this study showed that circulating neuronal biomarkers increased after endoscopic transsphenoidal pituitary surgery. For GFAP and tau, their increase after surgery was associated with the degree of preoperative suprasellar tumor extension, and the increase in tau was also associated with worse selfperceived fatigue 6 months after surgery. Despite being a small exploratory study, our data suggests that measurement of GFAP and tau in plasma might be of interest in future studies investigating the potential neuronal impact of pituitary tumor surgery.

\section{Funding}

The study was supported by grants from the Swedish state under the agreement between the Swedish government and the County Councils, the ALF-agreement (ALFGBG-719531 and ALFGBG-772591), and by grants from the Health \& Medical Care Committee of the Region Västra Götaland, Sweden and The Swedish Society of Medicine (SLS-884901). H Z is a Wallenberg Scholar supported by grants from the Swedish Research Council (\#201802532), the European Research Council (\#681712), the Swedish state under the agreement between the Swedish government and the County Councils, the ALF-agreement (\#ALFGBG-720931), and the Swedish Brain Foundation (\#FO2019-0228). K B holds the Torsten Söderberg Professorship in Medicine at the Royal Swedish Academy of Sciences and is supported by the Swedish Research Council (\#2017-00915), the Swedish Alzheimer Foundation (\#AF742881), Hjärnfonden, Sweden (\#FO2017-0243), and a grant (\#ALFGBG-715986) from the Swedish state under the agreement 
between the Swedish government and the County Councils, the ALF-agreement.

\section{Declaration of Competing Interest}

T S has received lecture fees from Abbott. G J has served as consultant for Shire and Astra Zeneca, and has received lecture fees from Eli Lilly, Ipsen, Novartis, Novo Nordisk, Merck Serono, Otsuka, and Pfizer. D S O has served as a consultant for Ipsen, Pfizer, NovoNordisk and Sandoz, and has received research grants from Sandoz. $\mathrm{K} B$ has served as a consultant or on advisory boards for Alector, Biogen, $\operatorname{CogRx}$, Lilly, MagQu, Novartis, and Roche Diagnostics, and is a co-founder of Brain Biomarker Solutions in Gothenburg AB, a GU Ventures-based platform company at the University of Gothenburg. $\mathrm{H} \mathrm{Z}$ has served on scientific advisory boards for Roche Diagnostics, Samumed, Wave, and $\operatorname{CogRx}$; has given lectures for symposia sponsored by Biogen and Alzecure; and is a co-founder of Brain Biomarker Solutions in Gothenburg AB, a GU Ventures-based platform company at the University of Gothenburg. None of the above is related to the work presented in this paper. All other authors have no relevant disclosures.

\section{Acknowledgements}

We are grateful to Nils-Gunnar Pehrsson and Christopher Backström at Statistiska Konsultgruppen for statistical support and to Peter Todd (Tajut Ltd., Kaiapoi, New Zealand) for third-party writing assistance in drafting of this manuscript, for which he received financial compensation from ALF-funding.

\section{References}

[1] Scheithauer BW, Gaffey TA, Lloyd RV, Sebo TJ, Kovacs KT, Horvath E, et al. Pathobiology of pituitary adenomas and carcinomas. Neurosurgery 2006;59:341-53. https://doi.org/10.1227/01.NEU.0000223437.51435.6E.

[2] Rizzoli P, Iuliano S, Weizenbaum E, Laws E. Headache in patients with pituitary lesions: a longitudinal cohort study. Neurosurgery 2016;78:316-23. https:// doi.org/10.1227/NEU.0000000000001067.

[3] Asa SL, Ezzat S. The pathogenesis of pituitary tumors. Annu Rev Pathol 2009;4:97-126. , http://10.1146/annurev.pathol.4.110807.092259.

[4] Karavitaki N, Cudlip S, Adams CBT, Wass JAH. Craniopharyngiomas. Endocr Rev 2006;27:371-97. https://doi.org/10.1210/er.2006-0002.

[5] Kinoshita Y, Tominaga A, Usui S, Arita K, Sakoguchi T, Sugiyama K, et al. The long-term recurrence of Rathke's cleft cysts as predicted by histology but not by surgical procedure. J Neurosurg 2016;125:1002-7. https://doi.org/10.3171/ 2015.8.JNS151282.

[6] King WA, Rodts GE, Becker DP, Mc Bride DQ. Microsurgical management of giant pituitary tumors. Skull Base Surgery 1996;6:17-26. https://doi.org/ 10.1055/s-2008-1058909.

[7] Losa M, Mortini P, Barzaghi R, Ribotto P, Terreni MR, Marzoli SB, et al. Early results of surgery in patients with nonfunctioning pituitary adenoma and analysis of the risk of tumor recurrence. J Neurosurg 2008;108:525-32. https://doi.org/10.3171/JNS/2008/108/3/0525.

[8] Olsson DS, Nilsson AG, Bryngelsson I-L, Trimpou P, Johannsson G, Andersson E. Excess mortality in women and young adults with non-functioning pituitary adenoma - a Swedish nationwide study. J Clin Endocrinol Metab 2015;100:2651-8. https://doi.org/10.1210/ic.2015-1475.

[9] Olsson DS, Andersson E, Bryngelsson I-L, Nilsson AG, Johannsson G. Excess mortality and morbidity in patients with craniopharyngioma, especially in patients with childhood-onset - a population-based study in Sweden. J Clin Endocrinol Metab 2014;100:467-74. https://doi.org/10.1210/ic.2014-3525.

[10] Penn DL, Burke WT, Laws ER. Management of non-functioning pituitary adenomas: surgery. Pituitary 2018;21:145-53. https://doi.org/10.1007/ s11102-017-0854-2.

[11] Gao Y, Zhong C, Wang Y, Xu S, Guo Y, Dai C, et al. Endoscopic versus microscopic transsphenoidal pituitary adenoma surgery: a meta-analysis. World J Surg Oncol 2014;12:94. , http://www.wjso.com/content/12/1/94.

[12] Capatina C, Christodoulides C, Fernandez A, Cudlip S, Grossman AB, Wass JAH, et al. Current treatment protocols can offer a normal or near-normal quality of life in the majority of patients with non-functioning pituitary adenomas. Clin Endocrinol 2012;78:86-93. https://doi.org/10.1111/j.1365-2265.2012.04449. x.

[13] Dekkers OM, van der Klaauw AA, Pereira AM, Biermasz NR, Honkoop PJ, Roelfsema F, et al. Quality of life is decreased after treatment for nonfunctioning pituitary macroadenoma. J Clin Endocrinol Metab 2006;91:3364-9. https://doi.org/10.1210/jc.2006-0003.
[14] Biermasz NR, Joustra SD, Donga E, Pereira AM, van Duinen N, van Dijk M, et al. Patients previously treated for nonfunctioning pituitary macroadenomas have disturbed sleep characteristics, circadian movement rhythm, and subjective sleep quality. J Clin Endocrinol Metab 2011;96:1524-32. https://doi.org/ 10.1210/jc.2010-2742.

[15] Joustra SD, Kruijssen E, Verstegen MJT, Pereira AM, Biermasz NR. Determinants of altered sleep-wake rhythmicity in patients treated for nonfunctioning pituitary macroadenomas. J Clin Endocrinol Metab 2014;99:4497-505. https://doi.org/10.1210/ic.2014-2602.

[16] Pereira AM, Schmid EM, Schutte PJ, Voormolen JHC, Biermasz NR, van Thiel SW, et al. High prevalence of long-term cardiovascular, neurological and psychosocial morbidity after treatment for craniopharyngioma. Clin Endocrinol 2005;62:197-204. $\quad$ https://doi.org/10.1111/i.13652265.2004.02196.x.

[17] Wijnen M, Olsson DS, van den Heuvel-Eibrink MM, Wallenius V, Janssen JA Delhanty PJ, et al. Efficacy and safety of bariatric surgery for craniopharyngioma-related hypothalamic obesity: a matched case-control study with 2 years of follow-up. Int J Obes (Lond) 2017;41:210-6. https://doi. org/10.1038/ijo.2016.195.

[18] Khalil M, Teunissen CE, Otto M, Piehl F, Sormani MP, Gattringer T, et al. Neurofilaments as biomarkers in neurological disorders. Nat Rev Neurol 2018;14:577-89. https://doi.org/10.1038/s41582-018-0058-z.

[19] Zetterberg H, Blennow K. Fluid biomarkers for mild traumatic brain injury and related conditions. Nat Rev Neurol 2016;12:563-74. https://doi.org/10.1038/ nrneurol.2016.127.

[20] Randall J, Mörtberg E, Provuncher GK, Fournier DR, Duffy DC, Rubertsson S, et al. Tau proteins in serum predict neurological outcome after hypoxic brain injury from cardiac arrest: results of a pilot study. Resuscitation 2013;84:351-6. https://doi.org/10.1016/i.resuscitation.2012.07.027.

[21] Andreasson U, Blennow K, Zetterberg H. Update on ultrasensitive technologies to facilitate research on blood biomarkers for central nervous system disorders. Alzheimers Dement (Amst) 2016;3:98-102. https://doi.org/ 10.1016/j.dadm.2016.05.005.

[22] Thelin EP, Zeiler FA, Ercole A, Mondello S, Büki A, Bellander B-M, et al. Serial sampling of serum protein biomarkers for monitoring human traumatic brain injury dynamics: a systematic review. Front Neurol 2017;8:300. https://doi. org/10.3389/fneur.2017.00300.

[23] Shahim P, Zetterberg H, Tegner Y, Blennow K. Serum neurofilament light as a biomarker for mild traumatic brain injury in contact sports. Neurology 2017;88:1788-94. https://doi.org/10.1212/WNL.0000000000003912.

[24] Ljungqvist J, Zetterberg H, Mitsis M, Blennow K, Skoglund T. Serum neurofilament light protein as a marker for diffuse axonal injury: results from a case series study. J Neurotrauma 2017;34:1124-7. https://doi.org/ 10.1089/neu.2016.4496.

[25] Stranjalis G, Korfias S, Psachoulia C, Boviatsis E, Kouyialis A, Protopappa D, et al. Serum S-100B as an indicator of early postoperative deterioration after meningioma surgery. Clin Chem 2005;51:202-7. https://doi.org/ 10.1373/clinchem.2004.039719.

[26] Einav S, Shoshan Y, Ovadia H, Matot I, Hersch M, Itshayek E. Early postoperative serum S100 beta levels predict ongoing brain damage after meningioma surgery: a prospective observational study. Crit Care 2006;10: R141. https://doi.org/10.1186/cc5058.

[27] Smets EM, Garssen B, Bonke B, De Haes JC. The Multidimensional Fatigue Inventory (MFI) psychometric qualities of an instrument to assess fatigue. J Psychosom Res 1995;39:315-25. https://doi.org/10.1016/0022-3999(94) 00125-O.

[28] Rohrer JD, Woollacott IOC, Dick KM, Brotherhood E, Gordon E, Fellows A, et al. Serum neurofilament light chain protein is a measure of disease intensity in frontotemporal dementia. Neurology 2016;87:1329-36. https://doi.org/ 10.1212/WNL.0000000000003154.

[29] Vickers AJ. The use of percentage change from baseline as an outcome in a controlled trial is statistically inefficient: a simulation study. BMC Med Res Methodol 2001;1:6. https://doi.org/10.1186/1471-2288-1-6.

[30] Eng LF, Vanderhaeghen JJ, Bignami A, Gerstl B. An acidic protein isolated from fibrous astrocytes. Brain Res 1971;28:351-4. https://doi.org/10.1016/00068993(71)90668-8.

[31] Missler U, Wiesmann M, Wittmann G, Magerkurth O, Hagenström H. Measurement of glial fibrillary acidic protein in human blood: analytical method and preliminary clinical results. Clin Chem 1999;45:138-41. https:// doi.org/10.1093/clinchem/45.1.138.

[32] Zetterberg H, Smith DH, Blennow K. Biomarkers of mild traumatic brain injury in cerebrospinal fluid and blood. Nat Rev Neurol 2013;9:201-10. https://doi. org/10.1038/nrneurol.2013.9.

[33] Dadas A, Washington J, Diaz-Arrastia R, Janigro D. Biomarkers in traumatic brain injury (TBI): a review. Neuropsychiatr Dis Treat 2018;14:2989-3000. http://dx.doi.org/10.2147\%2FNDT.S125620

[34] Takala RSK, Posti JP, Runtti H, Newcombe VF, Outtrim J, Katila AJ, et al. Glial fibrillary acidic protein and ubiquitin C-terminal hydrolase-L1 as outcome predictors in traumatic brain injury. World Neurosurg 2016;87:8-20. https:// doi.org/10.1016/i.wneu.2015.10.066.

[35] Hossain I, Mohammadian M, Takala RSK, Tenovuo O, Lagerstedt L, Ala-Seppala $\mathrm{H}$, et al. Early levels of glial fibrillary acidic protein and neurofilament light protein in predicting the outcome of mild traumatic brain injury. J Neurotrauma 2019;36:1551-60. https://doi.org/10.1089/neu.2018.5952.

[36] Trojanowski JQ, Schuck T, Schmidt ML, Lee VM. Distribution of tau proteins in the normal human central and peripheral nervous system. J Histochem 
Cytochem Off J Histochem Soc 1989;37:209-15. https://doi.org/10.1177/ 37.2.2492045.

[37] Olsson B, Zetterberg H, Hampel H, Blennow K. Biomarker-based dissection of neurodegenerative diseases. Prog Neurobiol 2011;95:520-34. https://doi.org/ 10.1016/j.pneurobio.2011.04.006.

[38] Mattsson N, Zetterberg H, Janelidze S, Insel PS, Andreasson U, Stomrud E, et al. Plasma tau in Alzheimer disease. Neurology 2016;87:1827-35. https://doi.org/ 10.1212/WNL.0000000000003246.

[39] Zetterberg H, Hietala MA, Jonsson M, Andreasen N, Styrud E, Karlsson I, et al. Neurochemical aftermath of amateur boxing. Arch Neurol 2006;63:1277-80. https://doi.org/10.1001/archneur.63.9.1277.

[40] Shahim P, Tegner Y, Wilson DH, Randall J, Skillbäck T, Pazooki D, et al. Blood biomarkers for brain injury in concussed professional ice hockey players. JAMA Neurol 2014;71:684-92. https://doi.org/10.1001/jamaneurol.2014.367.
[41] Liu Q Xie F, Siedlak SL, Nunomura A, Honda K, Moreira PI, et al. Neurofilament proteins in neurodegenerative diseases. Cell Mol Life Sci CMLS 2004;61:3057-75. https://doi.org/10.1007/s00018-004-4268-8.

[42] Evered L, Silbert B, Scott DA, Zetterberg H, Blennow K. Association of changes in plasma neurofilament light and tau levels with anesthesia and surgery: results from the capacity and Arcadian studies. JAMA Neurol 2018;75:542-7. https://doi.org/10.1001/jamaneurol.2017.4913.

[43] Deiner S, Baxter MG, Mincer JS, Sano M, Hall J, Mohammed I, et al. Human plasma biomarker responses to inhalational general anaesthesia without surgery. $\mathrm{Br} J$ Anaesth 2020;125:282-90. https://doi.org/10.1016/i. bja.2020.04.085.

[44] Alifier M, Olsson B, Andreasson U, Cullen NC, Czyżewska J, Jakubów P, et al. Cardiac surgery is associated with biomarker evidence of neuronal damage. J Alzheimers Dis 2020;74:1211-20. https://doi.org/10.3233/JAD-191165. 